\title{
A disciplina política educacional em cursos de pedagogia no Brasil: primeiras aproximações
}

\author{
Education policy discipline in pedagogy courses in Brazil: \\ first approaches
}

\section{La disciplina de política educativa en los cursos de pedagogía en Brasil: primeras aproximaciones}

\section{Silvana Stremel ${ }^{1}$ Jefferson Mainardes ${ }^{2}$}

\section{Resumo}

O trabalho apresenta uma análise exploratória da disciplina Política Educacional no currículo de Cursos de Pedagogia, de universidades públicas brasileiras. A amostra envolveu a análise de 128 disciplinas de 70 universidades públicas, de 85 ementas (de 50 universidades) e da bibliografia indicada em 44 ementas ou programas. Concluiu-se que: a) há uma variedade grande de designações para a disciplina (97 designações); b) na maioria dos cursos a disciplina é ofertada nos dois primeiros anos e a carga horária, na maioria dos currículos, é de 60 horas; c) foi possível identificar os conteúdos recorrentes nos programas e os aspectos que não são indicados nas ementas. O trabalho argumenta que a pesquisa sobre o ensino da disciplina Política Educacional é relevante, pois pode trazer informações importantes para a compreensão e melhoria tanto do ensino de Política Educacional quanto para a formação de pesquisadores para esse campo.

Palavras-chave: Política Educacional. Currículo. Curso de Pedagogia. 


\begin{abstract}
This paper presents an exploratory analysis of the Education Policy discipline in the curriculum of Pedagogy Courses of Brazilian public universities. The sample involved the analysis of 128 disciplines of 70 public universities, 85 syllabuses (50 universities) and the literature indicated in 44 syllabuses or programs. We concluded that: a) there is a wide variety of designations for the discipline (97 designations); b) in most courses the discipline is offered in the first two years and the load, in most curricula, is 60 hours; c) it was possible to identify recurring contents in programs and aspects that are not listed in the syllabuses. This paper argues that research on teaching the Education policy discipline is relevant because it can provide important information in order to understand and improve both the Education Policy teaching and researchers' education for this field.
\end{abstract}

Keywords: Education Policy. Curriculum. Pedagogy course.

\title{
Resumen
}

El artículo presenta un análisis exploratorio de la asignatura Política Educativa en el plan de estudios de el curso de pedagogía de las universidades públicas brasileñas. La muestra comprendió el análisis de 128 sujetos de 70 universidades públicas, 85 programas (de 50 universidades) y la bibliografía indicada en 44 programas. Se concluyó que: a) hay una amplia variedad de nombres para la asignatura (97 nombres); b) en la mayoría de los cursos de la disciplina se ofrece en los dos primeros años y la carga de trabajo en la mayoría de los planes de estudio, es de 60 horas; c) fue posible identificar el contenido que se repite en los programas y aspectos que no figuran en los programas. El artículo sostiene que la investigación sobre la disciplina política educativa de la educación es importante porque puede proporcionar información importante para comprender y mejorar tanto la enseñanza de política educativa quanto la formación de investigadores en este campo.

Palabras clave: Política Educativa; Currículo; Curso de Pedagogía. 


\section{Introdução}

O propósito desse trabalho é apresentar algumas reflexões iniciais sobre a disciplina Política Educacional (ofertada com diferentes denominações) em Cursos de Pedagogia de universidades públicas brasileiras.

O interesse em estudar a disciplina (ou disciplinas) da área de Política Educacional integra um projeto de pesquisa mais amplo que tem por objetivo analisar o processo histórico de constituição do campo acadêmico da Política Educacional no Brasil. Esse artigo pretende contribuir para as discussões sobre o ensino de Política Educacional e sobre a formação de pesquisadores para esse campo.

Inicialmente apresentamos um panorama da situação da pesquisa sobre o ensino de Política Educacional e a formação de pesquisadores para esse campo. Posteriormente, apresentamos a metodologia da pesquisa e a análise de características da disciplina Política Educacional nos currículos de Cursos de Pedagogia de 70 universidades brasileiras.

\section{Situando a pesquisa sobre o ensino de Política Educacional e a formação de pesquisadores para esse campo}

Esse artigo pretende contribuir para uma nova perspectiva de pesquisa no campo da Política Educacional, uma vez que, no levantamento bibliográfico realizado, constatamos que ainda são raros os estudos que tematizam aspectos relacionados ao ensino de Política Educacional e à formação de pesquisadores para esse campo. Trata-se de uma perspectiva nova, ainda em uma fase inicial, cuja motivação principal tem sido a chamada da Red Latinoamericana de Estudios Epistemológicos en Política Educativa - ReLePe para a realização do I Encuentro Latinoamericano de Profesores de Política Educativa (UNIFESP, julho de 2015). No referido encontro, 10 trabalhos enquadraram-se no eixo 1: Principais desafios teórico-metodológicos no desenvolvimento curricular da disciplina/espaço acadêmico Política Educacional na Graduação e PósGraduação (BONALS; ARENS; TRUJILLO, 2015; COSTA; MURANAKA; BORGHI, 2015; FLACH; MASSON, 2015; MARTIGNONI; 2015; MENDES, 2015; PRONKO, 2015; QUIANÉ; LÓPEZ, 2015; ROMERO; GARCIA, 2015; STREMEL; MAINARDES, 2015; VISACOVSKY, 2015). Além desses, localizou também o trabalho de Tello (2015).

Trata-se, assim, de um campo recente, o qual pode abranger uma série de investigações, tais como:

- o momento da criação da disciplina Política Educacional nos currículos de Cursos de Graduação;

- a identificação dos componentes curriculares que antecederam o que atualmente é designado como Política Educacional e as suas relações com o surgimento do campo e da disciplina de/sobre Política Educacional;

- a análise do conteúdo da disciplina explicitado em ementas e programas de disciplinas;

- a análise da bibliografia indicada nos programas;

- a análise de livros de natureza didática (manuais) elaborados para serem utilizados no ensino de Política Educacional.

Investigar o ensino de Política Educacional emerge como uma questão relevante na medida em que essa disciplina contribui no processo de formação de professores e pedagogos que já atuam ou atuarão nos sistemas de ensino. Essa disciplina pode proporcionar aos futuros educadores uma compreensão crítica das políticas educacionais, dos fundamentos das políticas, de aspectos essenciais relacionados à organização e legislação da educação brasileira, bem como da análise de políticas nacionais, estaduais e locais. Além disso, a disciplina Política Educacional pode servir como ponto de partida para a formação de futuros pesquisadores desse campo, principalmente quando optam pela realização de pesquisas sobre Política Educacional em nível de Pós-Graduação.

A seguir, apresentamos os procedimentos metodológicos da pesquisa. 


\section{Procedimentos metodológicos}

A presente pesquisa constitui-se como uma investigação de natureza exploratória. Para Gil (1999, p. 43), as pesquisas exploratórias têm como principal finalidade "desenvolver, esclarecer e modificar conceitos e ideias, tendo em vista, a formulação de problemas mais precisos ou hipóteses pesquisáveis para estudos posteriores". Ainda para Gil (2002, p. 41), as pesquisas exploratórias "têm como objetivo proporcionar maior familiaridade com o problema, com vistas a torná-lo mais explícito ou a construir hipóteses", esclarecendo ainda que o principal objetivo deste tipo de pesquisa é o "aprimoramento de ideias ou a descoberta de intuições". Trata-se assim, de uma primeira aproximação com o objeto de estudo.

A pesquisa envolveu a análise documental. Nesse tipo de procedimento de pesquisa a noção de documento é um conceito importante. Em uma abordagem ampla, uma grande diversidade de materiais pode ser considerada como documento ou fonte (RICHARDSON et al., 1999; CELLARD, 2014). Para Cellard (2014, p. 296-297), "pode tratar-se de textos escritos, mas também de documentos de natureza iconográfica ou cinematográfica, ou de qualquer outro tipo de testemunho registrado, objetos do cotidiano, elementos folclóricos, etc." (CELLARD, 2014, 296-297). No caso da presente pesquisa, os documentos consistiram em textos escritos, fontes primárias ${ }^{3}$ de acesso público, obtidos em arquivos digitais de Instituições de Ensino Superior. As fontes selecionadas para a sistematização e análise dos dados foram as seguintes: matrizes curriculares de Cursos de Pedagogia, planos e programas de ensino, projetos de curso e catálogos de cursos de universidades públicas brasileiras.

Na primeira etapa da pesquisa definiu-se o corpus de análise, com vistas a levantar as Instituições de Ensino Superior em funcionamento no Brasil. Para isso, contou-se com dados oficiais do Sistema do Ministério da Educação e-MEC ${ }^{4}$, o qual disponibiliza informações referentes às Instituições de Educação Superior e cursos cadastrados no país. Na consulta realizada ${ }^{5}$, optou-se por tomar como amostra as Instituições de Ensino Superior públicas de categoria administrativa: pública municipal, pública federal e pública estadual. O relatório da consulta listou 288 Instituições de Ensino Superior com a seguinte organização acadêmica: Faculdades (138 instituições), Universidades (103 instituições), Institutos Federais (40 instituições) e Centros Universitários (7 instituições). Para esse trabalho, definimos como corpus de análise apenas as 103 universidades públicas, visto que se trata de uma pesquisa ainda preliminar.

A segunda etapa da pesquisa envolveu a coleta do material empírico, a partir de consulta aos sites de cada uma das 103 universidades selecionadas. Nessa consulta, buscamos informações sobre os cursos ofertados, especificamente sobre o Curso de Pedagogia e seus dados curriculares mais atuais (em vigência) 6 . Todos os documentos curriculares localizados nos sites dessas universidades (matrizes curriculares, projetos de curso, planos e programas de ensino, catálogos de cursos das universidades) foram organizados em um banco de dados. A partir disso, identificaram-se as informações a respeito da disciplina de Política Educacional e as respectivas ementas. Durante essa etapa, as informações da amostragem (dados quantitativos sobre as universidades pesquisadas) foram agrupados, resultando no seguinte quadro geral:

3 As fontes primárias são produzidas pelos diretamente envolvidos ao fato, enquanto que as fontes secundárias provêm de sujeitos que não participaram do fato, mas que o reproduziram posteriormente (CELLARD, 2014).

4 Site: <http://emec.mec.gov.br>.

5 As buscas foram realizadas em março de 2015.

6 As buscas nos sites das universidades foram realizadas em março de 2015. Em alguns deles (sites de 18 universidades), as informaç̧ões sobre a estrutura curricular dos cursos estavam indisponíveis naquele momento (Quadro 1). 
Quadro 1 - Universidades públicas brasileiras pesquisadas

\begin{tabular}{|c|c|c|c|c|}
\hline Região & Estado & Universidades & $\begin{array}{l}\text { Universidades que ofertam ou não } \\
\text { o Curso de Pedagogia }\end{array}$ & $\begin{array}{l}\text { Universidades com ementas } \\
\text { disponíveis/ indisponíveis no site }\end{array}$ \\
\hline \multirow{7}{*}{ 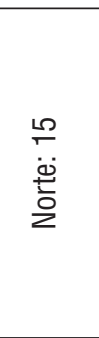 } & Acre: 1 & UFAC & \multirow{7}{*}{$\begin{array}{l}\text { Ofertam: } 14 \\
\text { Não ofertam: } 1\end{array}$} & \multirow{7}{*}{$\begin{array}{c}\text { Disponíveis: } 5 \\
\text { Indisponíveis: } 3 \\
\text { Informações curriculares } \\
\text { indisponíveis: } 6\end{array}$} \\
\hline & Amapá: 2 & UEAP, UNIFAP & & \\
\hline & Amazonas: 2 & UEA, UFAM & & \\
\hline & Pará: 5 & $\begin{array}{l}\text { UEPA, UFOPA, UFPA, UFRA, } \\
\text { UNIFESSPA }\end{array}$ & & \\
\hline & Rondônia:1 & UNIR & & \\
\hline & Roraima: 2 & UERR, UFRR & & \\
\hline & Tocantins: 2 & UFT, UNITINS & & \\
\hline \multirow{9}{*}{ 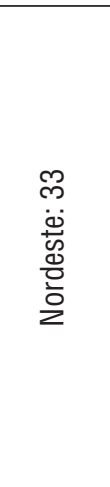 } & Alagoas: 3 & UFAL, UNCISAL, UNEAL & \multirow{9}{*}{$\begin{array}{l}\text { Ofertam: } 25 \\
\text { Não ofertam: } 8\end{array}$} & \multirow{9}{*}{$\begin{array}{c}\text { Disponíveis: } 12 \\
\text { Indisponíveis: } 3 \\
\text { Informações curriculares } \\
\text { indisponíveis: } 10\end{array}$} \\
\hline & Bahia: 8 & $\begin{array}{l}\text { UEFS, UESB, UESC, UFBA, } \\
\text { UFOB, UFRB, UFSB, UNEB }\end{array}$ & & \\
\hline & Ceará: 6 & $\begin{array}{l}\text { UECE, UFC, UFCA, UNILAB, } \\
\text { URCA, UVA }\end{array}$ & & \\
\hline & Maranhão: 3 & UEMA, UFMA, UNIVIMA & & \\
\hline & Paraíba: 3 & UEPB, UFCG, UFPB & & \\
\hline & Pernambuco: 4 & UFPE, UFRPE, UNIVASF, UPE & & \\
\hline & Piauí: 2 & UESPI, UFPI & & \\
\hline & $\begin{array}{l}\text { Rio Grande do } \\
\text { Norte: } 3\end{array}$ & UERN, UFERSA, UFRN & & \\
\hline & Sergipe: 1 & UFS & & \\
\hline \multirow{3}{*}{$\begin{array}{l}\stackrel{\bigcirc}{N} \\
\ddot{\overline{\bar{~}}}\end{array}$} & Paraná: 10 & $\begin{array}{l}\text { UEL, UEM, UENP, UEPG, } \\
\text { UFPR, UNESPAR, } \\
\text { UNICENTRO, UNILA, } \\
\text { UNIOESTE, UTFPR }\end{array}$ & \multirow{3}{*}{$\begin{array}{c}\text { Ofertam: } 18 \\
\text { Não ofertam: } 2\end{array}$} & \multirow{3}{*}{$\begin{array}{c}\text { Disponíveis: } 14 \\
\text { Indisponíveis: } 3 \\
\text { Não tem disciplina denominada } \\
\text { Política: } 1\end{array}$} \\
\hline & Rio Grande do Sul: 7 & $\begin{array}{l}\text { FURG, UERGS, UFCSPA, } \\
\text { UFPEL, UFRGS, UFSM, } \\
\text { UNIPAMPA }\end{array}$ & & \\
\hline & Santa Catarina: 3 & UDESC, UFFS, UFSC & & \\
\hline \multirow{4}{*}{ 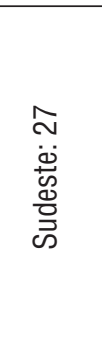 } & Espírito Santo: 1 & UFES & \multirow{4}{*}{$\begin{array}{c}\text { Ofertam: } 24 \\
\text { Não ofertam: } 3\end{array}$} & \multirow{4}{*}{$\begin{array}{c}\text { Disponíveis: } 16 \\
\text { Indisponíveis: } 7 \\
\text { Informações curriculares do curso } \\
\text { de Pedagogia indisponíveis: } 1\end{array}$} \\
\hline & Minas Gerais: 13 & $\begin{array}{l}\text { UEMG, UFJF, UFLA, UFMG, } \\
\text { UFOP, UFSJ, UFTM, UFU, } \\
\text { UFV, UFVJM, UNIFAL, UNIFEI, } \\
\text { UNIMONTES }\end{array}$ & & \\
\hline & Rio de Janeiro: 6 & $\begin{array}{l}\text { UENF, UERJ, UFF, UFRJ, } \\
\text { UFRRJ, UNIRIO }\end{array}$ & & \\
\hline & São Paulo: 7 & $\begin{array}{c}\text { UFABC, UFSCar, UNESP, } \\
\text { UNICAMP, UNIFESP, USCS, USP }\end{array}$ & & \\
\hline \multirow{4}{*}{ 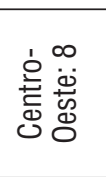 } & Distrito Federal: 1 & UnB & \multirow{4}{*}{$\begin{array}{c}\text { Ofertam: } 8 \\
\text { Não ofertam: } 0\end{array}$} & \multirow{4}{*}{$\begin{array}{c}\text { Disponíveis: } 3 \\
\text { Indisponíveis: } 4 \\
\text { Informações curriculares } \\
\text { indisponíveis: } 1\end{array}$} \\
\hline & Goiás: 2 & UEG, UFG & & \\
\hline & Mato Grosso do Sul: 3 & UEMS, UFGD, UFMS & & \\
\hline & Mato Grosso: 2 & UFMT, UNEMAT & & \\
\hline \multicolumn{3}{|c|}{ Total de universidades: 103} & $\begin{array}{c}\text { Total - ofertam: } 89 \\
\text { Total - não ofertam: } 14\end{array}$ & $\begin{array}{l}\text { Total de universidades com ementas } \\
\text { disponíveis no site: } 50 \\
\text { Total de universidades com ementas } \\
\text { indisponíveis: } 20 \\
\text { Total de universidades com } \\
\text { informações curriculares } \\
\text { indisponíveis: } 18 \\
\text { Total de universidades com Curso de } \\
\text { Pedagogia que não tem a disciplina } \\
\text { Política Educacional: } 1\end{array}$ \\
\hline
\end{tabular}

Fonte: Organizado pelos autores com base nos dados do sistema e-MEC e sites das universidades públicas brasileiras. 
Conforme apresentado no quadro 1, das 103 universidades, 89 ofertam o Curso de Pedagogia. Dessas 89 universidades, em 50 delas as informações curriculares e as ementas das disciplinas que compõem a grade curricular estavam disponibilizadas no site da instituição. Em 20 universidades, a estrutura curricular estava publicizada, mas as ementas não. Em outras 18 universidades os dados estavam indisponíveis no momento da realização da coleta de dados. Em uma das universidades pesquisadas, a organização curricular não apresentava a disciplina Política Educacional (ou outra variação de designação para se referir a ela), uma vez que o currículo estruturava-se por blocos e eixos temáticos, sendo que as questões de Política Educacional eram trabalhadas no eixo "Escola, Cultura e Sociedade".

Assim, do total de universidades pesquisadas, foram analisadas as informações curriculares (denominação da disciplina, carga horária e etapa em que é cursada) de 70 instituições e as ementas de 50 dessas (que estavam disponíveis). É importante salientar que algumas universidades ofertavam o Curso de Pedagogia em mais de um campus. Na maioria dos casos, os projetos de curso eram distintos em cada campus.

Em algumas matrizes curriculares, havia a oferta de mais de uma disciplina de/sobre Política Educacional. Portanto, das instituições com informações curriculares disponíveis (70 instituições), foram identificadas 128 disciplinas de/sobre Política Educacional, sendo que 85 possuíam ementa disponível e outras 43 não estavam disponibilizadas. Das 85 disciplinas, 41 indicavam apenas a ementa e 44 apresentavam a ementa com a bibliografia. As informações sobre a disciplina de Política Educacional (denominação, carga horária, etapa em que é cursada), bem como as ementas e a bibliografia foram sistematizadas em um quadro que serviu de subsídio para a organização dos dados e a análise apresentada a seguir, constituindo a terceira etapa da pesquisa. Nessa última etapa, a pesquisa envolveu a utilização do software Sphinx ${ }^{7}$ para a análise lexical dos dados das ementas.

\section{A disciplina Política Educacional nos currículos dos cursos de Pedagogia}

Conforme mencionado acima, na análise das informações curriculares da disciplina de/sobre Política educacional considerou-se 5 aspectos: denominação, carga horária, etapa em que é ofertada, ementa e bibliografia.

Em relação à denominação da disciplina constatamos que uma diversidade de designações é empregada, conforme apresentado na lista a seguir, cujo número entre parênteses indica a quantidade de vezes que a nomenclatura foi empregada nas 128 disciplinas:

1. Política Educacional (9)

2. Políticas Educacionais (5)

3. Estrutura e Funcionamento da Educação Básica (5)

4. Organização da Educação Brasileira (3)

5. Políticas Públicas e Educação (3)

6. Políticas Públicas em Educação (3)

7. Legislação da Educação Básica (2)

8. Legislação Educacional (2)

9. Organização da Educação no Brasil (2)

10. Organização e Funcionamento do Sistema Educacional - Educação Básica (2)

11. Política e Organização da Educação Básica (2)

12. Política Educacional Brasileira (2)

70 Sphinx é um sistema para pesquisa e análise de dados desenvolvido na França e comercializado desde 1989. No Brasil, tem sido adaptado e utilizado desde 1995. Dentre as várias ferramentas e funções, esse software oferece recursos de análise de textos, tais como: análise a partir de categorias de uma variável, análise temática, análise de léxicos, análise de segmentos repetidos, entre outras. (FREITAS et al., 2008). 
13. Política Educacional I (2)

14. Política Educacional II (2)

15. Políticas Públicas da Educação (2)

16. Ciência Política e Educação

17. Educação Brasileira: Legislação e Sistema

18. Estado e Políticas Educacionais

19. Estrutura e Funcionamento da Educação Brasileira

20. Estrutura e Funcionamento do Ensino

21. Legislação Aplicada à Educação Básica

22. Legislação da Educação Brasileira

23. Legislação do Ensino

24. Organização da Educação Brasileira e Legislação I

25. Organização da Educação Brasileira e Legislação II

26. Organização da Educação Nacional

27. Organização do Ensino no Brasil

28. Organização e Funcionamento da Educação Básica

29. Organização e Funcionamento da Educação Brasileira

30. Organização e Gestão da Educação Básica

31. Organização e Política da Educação Brasileira

32. Organização Educacional e Escolar I

33. Organização Educacional e Escolar II

34. Organização Escolar Brasileira

35. Política da Educação no Brasil

36. Política e Educação

37. Política e Gestão da Educação

38. Política e Gestão Educacional I

39. Política e Gestão Educacional II

40. Política e Legislação da Educação Básica

41. Política e Legislação Educacional

42. Política e Legislação Educacional Brasileira

43. Política e o Estado Brasileiro

44. Política e Organização da Educação Básica I

45. Política e Organização da Educação Básica II

46. Política e Organização da Educação Básica no Brasil

47. Política e Organização da Educação Brasileira

48. Política e Organização da Educação I

49. Política e Planejamento da Educação

50. Política e Planejamento Educacional

51. Política e Planejamento Educacional I

52. Política e Planejamento Educacional II

53. Política e Planejamento na Educação Básica

54. Política Educacional - Ensino Fundamental

55. Política Educacional Brasileira I

56. Política Educacional Brasileira II

57. Política Educacional e Legislação da Educação Infantil e Ensino Fundamental 
58. Política Educacional e Legislação do Ensino no Brasil

59. Política Educacional e Organização da Educação Básica I

60. Política Educacional e Organização da Educação Básica II

61. Política Educacional e Organização da Educação Brasileira

62. Política Educacional e Organização do Ensino no Brasil

63. Política Educacional: Organização da Educação Brasileira

64. Política Pública da Educação I

65. Política Pública da Educação II

66. Políticas de Educação Básica

67. Políticas de Educação Infantil

68. Políticas e Legislação da Educação

69. Políticas e Legislação da Educação Básica

70. Políticas e organização da Educação Básica

71. Políticas e Planejamento da Educação no Brasil

72. Políticas Educacionais Brasileiras

73. Políticas Educacionais e Educação Básica

74. Políticas Educacionais I

75. Políticas Educacionais II

76. Políticas Educacionais, Organização e Funcionamento da Educação Básica

77. Políticas para a Educação Básica

78. Políticas Públicas

79. Políticas Públicas da Educação Brasileira

80. Políticas Públicas de Educação

81. Políticas Públicas de Educação para a Infância

82. Políticas Públicas e Gestão da Educação

83. Políticas Públicas e Gestão da Educação Brasileira

84. Políticas Públicas e Gestão Educacional: Docência e Diversidade Cultural

85. Políticas Públicas e Gestão Educacional: Identidade do Pedagogo nos Processos Escolares e Não Escolares

86. Políticas Públicas e Legislação da Educação I

87. Políticas Públicas e Legislação da Educação II

88. Políticas Públicas e Legislação do Ensino Básico

89. Políticas Públicas e Legislação Educacional

90. Políticas Públicas e Legislação em Educação

91. Políticas Públicas Educacionais

92. Políticas Públicas em Educação I

93. Políticas Públicas em Educação II

94. Políticas Públicas na Educação Básica

95. Políticas Públicas para a Infância e a Juventude

96. Políticas Públicas para Educação Básica

97. Políticas, Estado e Educação

O número elevado de designações empregadas indica uma certa dispersão do campo, pois os termos "Política Educacional" ou "Políticas Educacionais" e ainda "Políticas e gestão da educação" são termos mais comumente utilizados para referir-se a esse campo, seja para designar grupos de pesquisa, linhas de pesquisa em Programas de Pós-Graduação em Educação, disciplinas na Graduação e Pós-Graduação, etc. No entanto, 
no momento da criação de novos cursos de Pedagogia ou da reestruturação curricular de cursos já existentes, uma série de fatores interfere na composição das matrizes curriculares, tais como: o quadro docente da instituição, a tradição em pesquisa e pós-graduação, etc.

Com relação à carga horária, observa-se que na maioria das instituições, a disciplina relacionada à política educacional possui 60 horas/aula (Tabela 1). No entanto, deve-se destacar que algumas instituições possuem mais de uma disciplina de Política Educacional, como é o caso da Universidade Estadual do Sudoeste da Bahia (UESB) - Campus de Vitória da Conquista, que oferta as disciplinas Política Educacional I (60 horas) e Política Educacional II (60 horas). Na Universidade Federal de Sergipe (UFS) são ofertadas as disciplinas Política e Gestão Educacional I (60 horas), Política e Gestão Educacional II (60 horas), Política e Educação (60 horas) e Estrutura e Funcionamento da Educação Básica (60 horas). Na Universidade de São Paulo (USP) - Ribeirão Preto, há duas disciplinas: Política Educacional e Organização da Educação Básica I (90 horas) e Política Educacional e Organização da Educação Básica II (60 horas). Esses são apenas alguns exemplos de universidades que oferecem mais de uma disciplina de Política Educacional.

Tabela 1 - Carga horária das disciplinas

\begin{tabular}{|c|c|}
\hline Carga Horária $(\mathrm{CH})$ & No $^{0}$ de disciplinas \\
\hline $60 \mathrm{~h}$ & 59 \\
\hline $75 \mathrm{~h}$ & 10 \\
\hline $72 \mathrm{~h}$ & 10 \\
\hline $68 \mathrm{~h}$ & 5 \\
\hline $102 \mathrm{~h}$ & 5 \\
\hline $45 \mathrm{~h}$ & 4 \\
\hline $80 \mathrm{~h}$ & 3 \\
\hline $136 \mathrm{~h}$ & 3 \\
\hline $90 \mathrm{~h}$ & 3 \\
\hline $30 \mathrm{~h}$ & 2 \\
\hline $64 \mathrm{~h}$ & 1 \\
\hline $128 \mathrm{~h}$ & 1 \\
\hline $120 \mathrm{~h}$ & 1 \\
\hline $108 \mathrm{~h}$ & 1 \\
\hline $54 \mathrm{~h}$ & 1 \\
\hline $34 \mathrm{~h}$ & 9 \\
\hline Não indica a CH & 128 \\
\hline Total & \\
\hline
\end{tabular}

Fonte: Organizada pelos autores.

As grades curriculares estavam organizadas em períodos/semestres ou em ano/série. Para fins de apresentação dos dados, na tabela a seguir consideramos o primeiro e segundo período/semestre equivalente ao $1^{\circ}$ ano de curso e assim por diante. A maior parte é ofertada nos dois primeiros anos do curso (Tabela 2). 
Tabela 2 - Etapa em que a disciplina é cursada

\begin{tabular}{|c|c|}
\hline Etapas & $\mathrm{N}^{0}$ \\
\hline $1^{\mathrm{a}}$ ano de curso & 38 \\
\hline $2^{\mathrm{a}}$ ano de curso & 50 \\
\hline $3^{\mathrm{a}}$ ano de curso & 18 \\
\hline $4^{\mathrm{a}}$ ano de curso & 19 \\
\hline Não indica a etapa & 3 \\
\hline Total & 128 \\
\hline
\end{tabular}

Fonte: Organizada pelos autores.

A partir da análise de 85 ementas (de 50 universidades diferentes), foi possível identificar os segmentos e palavras recorrentes (Tabelas 3 e 4). Consideramos que as ementas revelam aspectos importantes sobre como as disciplinas de Política Educacional são concebidas nos currículos dos Cursos de Pedagogia. No entanto, sabe-se que, na prática, tais ementas são ajustadas à realidade do professor responsável, bem como da realidade das turmas e características da instituição.

Combinando os dados das tabelas 3 e 4, pode-se compreender que, de modo geral, os tópicos mais presentes nas ementas são os seguintes:

a) Aspectos relacionados à organização da educação brasileira (sistema educacional brasileiro, níveis, modalidades);

b) Aspectos da legislação educacional (Constituições Federais, leis nacionais referentes à educação, LDB, PNE, Resoluções, Pareceres);

c) Reformas educacionais;

d) Gestão da educação;

e) Políticas e Programas da Educação Básica;

f) Financiamento da educação;

g) Estado e educação.

Observou-se pouca incidência de termos relacionados a aspectos teóricos, epistemológicos e de metodologias e abordagens de pesquisa no campo da política educacional. É possível que em virtude da carga horária relativamente pequena da disciplina na Graduação em Pedagogia (60 h, na maioria das instituições incluídas na amostra), as referidas questões de natureza teórica sejam menos contempladas ou atendidas de forma mais breve. É possível também que tais questões constituam o conteúdo da Política Educacional em nível de Pós-Graduação. 
Tabela 3 - Segmentos recorrentes nas 85 ementas da amostra

\begin{tabular}{|c|c|}
\hline Segmentos & $\mathrm{N}^{0}$ de repetições \\
\hline Educação Básica & 57 \\
\hline Políticas públicas & 48 \\
\hline Políticas educacionais & 34 \\
\hline Sistema educacional / de ensino & 30 \\
\hline Ensino Fundamental & 25 \\
\hline Educação Infantil & 24 \\
\hline Política educacional & 22 \\
\hline Organização da educação & 22 \\
\hline Legislação do ensino / da educação / brasileira & 21 \\
\hline Educação Nacional & 15 \\
\hline Modalidades da educação & 15 \\
\hline Educação brasileira & 13 \\
\hline Financiamento da educação & 13 \\
\hline Políticas e educação & 12 \\
\hline Estado e políticas / sociedade & 11 \\
\hline Educação brasileira & 10 \\
\hline Lei de Diretrizes e Bases & 10 \\
\hline Reformas educacionais & 10 \\
\hline Ensino Superior & 9 \\
\hline Gestão da educação & 8 \\
\hline América Latina & 8 \\
\hline Ensino Médio & 8 \\
\hline Estrutura e funcionamento & 8 \\
\hline Constituição 1988 & 6 \\
\hline Plano Nacional da Educação & 5 \\
\hline Movimentos sociais & 4 \\
\hline Política e gestão & 4 \\
\hline Políticas da educação básica & 4 \\
\hline Profissionais da educação & 4 \\
\hline Sistema escolar & 4 \\
\hline Avaliação da educação & 3 \\
\hline Constituições federais & 3 \\
\hline Contexto internacional & 3 \\
\hline Contexto sociopolítico & 3 \\
\hline Direito à educação & 3 \\
\hline Diretrizes Curriculares & 3 \\
\hline Estatuto da Criança e do Adolescente & 3 \\
\hline Educação e sociedade & 3 \\
\hline Espaços educativos & 3 \\
\hline Estado brasileiro & 3 \\
\hline Gestão escolar & 3 \\
\hline Organismos Internacionais & 3 \\
\hline Planejamento Educacional & 3 \\
\hline Política social & 3 \\
\hline Participação da sociedade & 3 \\
\hline
\end{tabular}

Fonte: Organizada pelos autores a partir do relatório de análise lexical do software Sphinx. 
Tabela 4 - Palavras recorrentes nas 85 ementas da amostra






\begin{tabular}{|c|c|}
\hline Internacional/is & $9 / 9$ \\
\hline Médio & $9 / 8$ \\
\hline Plano & $9 / 7$ \\
\hline Poder & $9 / 6$ \\
\hline Atual/ais & $8 / 8$ \\
\hline Perspectivas & $8 / 8$ \\
\hline Trabalho & $8 / 8$ \\
\hline Desenvolvimento & $8 / 7$ \\
\hline Projetos & $8 / 7$ \\
\hline Construção & $8 / 6$ \\
\hline Avaliação & $7 / 7$ \\
\hline Fundamentos & $7 / 7$ \\
\hline Histórica & $7 / 7$ \\
\hline Princípios & $7 / 7$ \\
\hline Programa & $7 / 7$ \\
\hline Público & $7 / 7$ \\
\hline Privado/s & $7 / 7$ \\
\hline Crítica/o/s & $7 / 7$ \\
\hline 9394/96 & $7 / 6$ \\
\hline Escolares & $7 / 5$ \\
\hline Cidadania & $6 / 6$ \\
\hline Estadual & $6 / 6$ \\
\hline Históricos & $6 / 6$ \\
\hline Legais & $6 / 6$ \\
\hline Movimentos & $6 / 6$ \\
\hline Vigente/s & $6 / 6$ \\
\hline Conceito/s & $6 / 6$ \\
\hline Professores & $6 / 6$ \\
\hline Profissional & $6 / 6$ \\
\hline Pública & $6 / 6$ \\
\hline Reforma & $6 / 6$ \\
\hline Educativa/s & $6 / 6$ \\
\hline Prática/s & $6 / 6$ \\
\hline Nível & $6 / 5$ \\
\hline Atendimento & $6 / 4$ \\
\hline Descentralização & $6 / 4$ \\
\hline Constituições & $5 / 5$ \\
\hline Teórico/a/as & $5 / 5$ \\
\hline História & $5 / 5$ \\
\hline América / Latina & $5 / 5$ \\
\hline Democracia & $5 / 5$ \\
\hline Pedagógico & $5 / 5$ \\
\hline Projeto & $5 / 5$ \\
\hline Qualidade & $5 / 5$ \\
\hline Governo/s & $5 / 5$ \\
\hline Implementação/implementadas & $5 / 5$ \\
\hline Escolas & $5 / 4$ \\
\hline Federais & $5 / 4$ \\
\hline Legal & $5 / 4$ \\
\hline Tendências & $5 / 4$ \\
\hline Neoliberal/is & $5 / 4$ \\
\hline Diversidade/s & $5 / 4$ \\
\hline Regulação & $5 / 3$ \\
\hline Articulação & $4 / 4$ \\
\hline Estatuto & $4 / 4$ \\
\hline
\end{tabular}




\begin{tabular}{|c|c|}
\hline Globalização & $4 / 4$ \\
\hline Papel & $4 / 4$ \\
\hline Participação & $4 / 4$ \\
\hline Profissionais & $4 / 4$ \\
\hline Propostas & $4 / 4$ \\
\hline Realidade & $4 / 4$ \\
\hline Financeira/os & $4 / 4$ \\
\hline Visão & $4 / 4$ \\
\hline Determinante/s & $4 / 4$ \\
\hline Demanda/s & $4 / 4$ \\
\hline Transformação/ões & $4 / 4$ \\
\hline Educativos & $4 / 3$ \\
\hline Curriculares & $4 / 3$ \\
\hline Carreira & $3 / 3$ \\
\hline Condicionantes & $3 / 3$ \\
\hline Definição & $3 / 3$ \\
\hline Democratização & $3 / 3$ \\
\hline Economia & $3 / 3$ \\
\hline Elaboração & $3 / 3$ \\
\hline Espaços & $3 / 3$ \\
\hline Formulação & $3 / 3$ \\
\hline Função & $3 / 3$ \\
\hline Governamentais & $3 / 3$ \\
\hline Impactos & $3 / 3$ \\
\hline Instituições & $3 / 3$ \\
\hline Municipalização & $3 / 3$ \\
\hline Resolução/ões & $3 / 3$ \\
\hline Normas & $3 / 3$ \\
\hline Normativos & $3 / 3$ \\
\hline Pedagógicos & $3 / 3$ \\
\hline Federada/Federativa/Federativas & $3 / 3$ \\
\hline Possibilidades & $3 / 3$ \\
\hline Públicos & $3 / 3$ \\
\hline Pedagogo & $3 / 2$ \\
\hline Curricular & $3 / 2$ \\
\hline Identidade & $3 / 2$ \\
\hline Capitalista & $2 / 2$ \\
\hline Centralização & $2 / 2$ \\
\hline Colaboração & $2 / 2$ \\
\hline Condições & $2 / 2$ \\
\hline Conjuntura & $2 / 2$ \\
\hline Conselhos & $2 / 2$ \\
\hline Conservadora & $2 / 2$ \\
\hline Controle & $2 / 2$ \\
\hline Democrática & $2 / 2$ \\
\hline Direitos & $2 / 2$ \\
\hline ECA & $2 / 2$ \\
\hline EJA & $2 / 2$ \\
\hline Estados & $2 / 2$ \\
\hline Etapas & $2 / 2$ \\
\hline Éticos & $2 / 2$ \\
\hline Expansão & $2 / 2$ \\
\hline Filosóficos & $2 / 2$ \\
\hline Normativa/normatização & $2 / 2$ \\
\hline Organizacional/is & $2 / 2$ \\
\hline
\end{tabular}




\begin{tabular}{|c|c|}
\hline FUNDEB & $2 / 2$ \\
\hline Fundos & $2 / 2$ \\
\hline Gestor & $2 / 2$ \\
\hline Higienista & $2 / 2$ \\
\hline Implicações & $2 / 2$ \\
\hline Inclusão & $2 / 2$ \\
\hline Iniciativas & $2 / 2$ \\
\hline Instâncias & $2 / 2$ \\
\hline Intervenção & $2 / 2$ \\
\hline Liberais & $2 / 2$ \\
\hline Manutenção & $2 / 2$ \\
\hline Metas & $2 / 2$ \\
\hline Micro & $2 / 2$ \\
\hline Modelos & $2 / 2$ \\
\hline Didáticas/os & $2 / 2$ \\
\hline Diferenças/diferente & $2 / 2$ \\
\hline Moderno & $2 / 2$ \\
\hline Multilaterais & $2 / 2$ \\
\hline PNE & $2 / 2$ \\
\hline Socioeconômico & $2 / 2$ \\
\hline Valorização & $2 / 2$ \\
\hline Abordagem/ens & $2 / 2$ \\
\hline Gerencial/gerenciamento & $2 / 2$ \\
\hline Neoliberalismo & $2 / 1$ \\
\hline Modernização & $2 / 1$ \\
\hline Influência & $2 / 1$ \\
\hline Ambiguidades & $1 / 1$ \\
\hline Autonomia & $1 / 1$ \\
\hline Capitalismo & $1 / 1$ \\
\hline Colegiada & $1 / 1$ \\
\hline Competências & $1 / 1$ \\
\hline Conhecimento & $1 / 1$ \\
\hline Constitucional & $1 / 1$ \\
\hline Criticamente & $1 / 1$ \\
\hline Decretos & $1 / 1$ \\
\hline Demografia & $1 / 1$ \\
\hline Desconstrução & $1 / 1$ \\
\hline Desigualdades & $1 / 1$ \\
\hline Desenvolvimentista & $1 / 1$ \\
\hline Diagnóstico & $1 / 1$ \\
\hline Dilemas & $1 / 1$ \\
\hline Docência & $1 / 1$ \\
\hline Educadores & $1 / 1$ \\
\hline Efeitos & $1 / 1$ \\
\hline Embate & $1 / 1$ \\
\hline Epistemologia & $1 / 1$ \\
\hline Escolaridade & $1 / 1$ \\
\hline Escolarização & $1 / 1$ \\
\hline Estatal & $1 / 1$ \\
\hline Evasão & $1 / 1$ \\
\hline Evolução & $1 / 1$ \\
\hline FNDE & $1 / 1$ \\
\hline Hegemônicos & $1 / 1$ \\
\hline Historicidades & $1 / 1$ \\
\hline Homogeneidades & $1 / 1$ \\
\hline
\end{tabular}




\begin{tabular}{|c|c|}
\hline Inclusiva & $1 / 1$ \\
\hline Indicadores & $1 / 1$ \\
\hline Interdependência & $1 / 1$ \\
\hline Marxistas & $1 / 1$ \\
\hline Monitoramento & $1 / 1$ \\
\hline PCN & $1 / 1$ \\
\hline Referenciais & $1 / 1$ \\
\hline Regulada & $1 / 1$ \\
\hline Sindicais & $1 / 1$ \\
\hline Tipologias & $1 / 1$ \\
\hline Wefare / State & $1 / 1$ \\
\hline
\end{tabular}

Fonte: Organizada pelos autores a partir do relatório de análise lexical do software Sphinx.

Observação: Para as palavras com apenas uma recorrência, selecionamos aquelas que consideramos mais significativas.

A presente pesquisa envolveu também a análise da bibliografia de 44 disciplinas (ementas com bibliografia ou programas das disciplinas) de 28 universidades diferentes (Tabela 5), o que constitui uma amostra reduzida diante do total de 85 ementas. Constatou-se que as obras mais citadas foram: Da Nova LDB ao Fundeb: por uma outra política educacional (SAVIANI, 2007); Educação escolar: políticas, estruturas e organização (LIBÂNEO; OLIVEIRA; TOSCHI, 2003); Da Nova LDB ao Plano Nacional de Educação (SAVIANI, 1998); A educação como política pública (AZEVEDO, 1997); LDB interpretada: diversos olhares se entrecruzam (BRZEZINSKI, 1997); Organização do ensino no Brasil: níveis e modalidades na Constituição Federal e na LDB (OLIVEIRA; ADRIÃO, 2002); A Nova Lei da Educação: trajetórias, limites e perspectivas (SAVIANI, 1997) e Política Educacional (SHIROMA; MORAES; EVANGELISTA, 2000). As referências de artigos de periódicos são bastante reduzidas nas ementas e programas analisados. Em parte, isso se deve ao fato de que, nas bibliografias das ementas e programas, geralmente priorizam-se as referências de livros. Entre os livros que podem ser considerados como manuais ou livros com finalidades didáticas no ensino de Política Educacional destaca-se o livro de Libâneo, Oliveira e Toschi (2003)

Ainda com relação à bibliografia para o ensino de Política Educacional, destacamos que os desafios para a utilização de um livro para a disciplina é algo complexo, pois se trata de uma disciplina abrangente, que envolve uma grande diversidade de temáticas. Além disso, uma parte do conteúdo da disciplina refere-se a aspectos legais que são bastante dinâmicos e que demandam constante atualização.

Tabela 5 - Bibliografia mais recorrente em 44 programas de disciplinas e ementas com bibliografia

\begin{tabular}{|c|c|}
\hline Autor/Obra & $N^{0}$ de indicações \\
\hline SAVIANI, D. A Nova Lei da Educação: trajetórias limites e perspectivas & 15 \\
\hline AZEEVEEDO, J. L. A educação çomo política pública & 13 \\
\hline BRZEZINSKY, I. (Org.). LDB interpretada: diversos olhares se entrecruzam & 12 \\
\hline SAVIANI, D. Da Nova LDB ao novo plano nacional de educação: por uma outra política educacional & 11 \\
\hline SHIROMA, E. O.; MORAES, M. C. M.; EVANGELISTA, O. Política educacional & 7 \\
\hline SAVIANI, D. Da nova LDB ao FUNDEB: por uma outra política educacional & 7 \\
\hline OLIVEIRA, R. M.; ADRIÃO, T. (Orgs.). Organização do ensino no Brasil: níveis e modalidades na Constituição Federal e na LDB & 6 \\
\hline BRANDÃO, C. F. LDB: passo a passo & 5 \\
\hline TOMASI, L., WARDE, M. J.; HADDAD, S. (Org.). O Banco Mundial e as políticas educacionais & 5 \\
\hline
\end{tabular}

8 No levantamento realizado para a presente pesquisa foram catalogados 13 livros que podem ser considerados livros de natureza didática para 0 ensino de Política Educacional, principalmente em nível de Graduação (MARTINS, 1993; AZEVEDO, 1997; SHIROMA; MORAES; EVANGELISTA, 2000; VIEIRA; ALBUQUERQUE, 2001; LIBÂNEO; OLIVEIRA; TOSCHI, 2003; VIEIRA; FARIAS, 2007; NEY, 2008; KFOURI, 2009; VIEIRA, 2009; BRUEL, 2010; SOUZA; GOUVEIA; TAVARES, 2011; SANTOS, 2012; CARVALHO, 2012). 0 livro de Libâneo, Oliveira e Toschi teve a sua primeira edição em 2003. Em 2012, atingiu a sua $10^{a}$ edição. 


\begin{tabular}{|c|c|}
\hline GENTILI, P.; SILVA, T. T. da (Orgs.). Neoliberalismo, qualidade total e educação & 5 \\
\hline OLIVEIRA, D. A.; DUARTE, M. R. T. (Org.). Política e trabalho na escola: administração dos sistemas públicos de educação básica & 5 \\
\hline DAVIES, N. 0 Fundef e 0 orçamento da educação: desvendando a caixa preta & 4 \\
\hline DOURADO, L. F.; PARO, V. H. (Orgs.). Políticas públicas e educação básica & 4 \\
\hline FAVERO, 0. (Org.). A Educação nas constituintes brasileiras 1823-1988 & 4 \\
\hline MAINARDES, J. Abordagem do ciclo de políticas: uma contribuição para a análise de políticas educacionais & 4 \\
\hline MENEZES, J. G. C. (Org.). Estrutura e Funcionamento da Educação Básica & 4 \\
\hline PERONI, V. M. V. Política educacional e papel do Estado no Brasil dos anos 90 & 4 \\
\hline ROMANELLI, 0. História da Educação no Brasil: 1930-1973 & 4 \\
\hline DEMO, P. A nova LDB: ranços e avanços & 4 \\
\hline SADER, E.; GENTILI, P. (Org.). Pós-Neoliberalismo: as políticas sociais e o Estado democrático & 4 \\
\hline DAVIES, N. Financiamento da educação. Novos ou velhos desafios? & 3 \\
\hline DAVIES, N. Legislação educacional federal básica & 3 \\
\hline FRIGOTTO, G. Educação e a crise do capitalismo real & 3 \\
\hline OLIVEIRA, D. A. (Org.). Gestão democrática da educação: desafios contemporâneos & 3 \\
\hline OLIVEIRA, R. P. de (Org.). Política educacional: impasses e alternativa & 3 \\
\hline POPEKEWITZ, T. S. Reforma Educacional: uma política sociológica: poder e conhecimento em educação & 3 \\
\hline SILVA, E. B. da (Org.). A Educação Básica pós-LDB & 3 \\
\hline SILVA, M. A. Intervenção e consentimento: a política educacional do Banco Mundial & 3 \\
\hline VIEIRA, S. L.; FARIAS, I. M. S. Política educacional no Brasil: uma introdução histórica & 3 \\
\hline VIEIRA, S. L. (Org.). Estrutura e funcionamento da educação básica & 3 \\
\hline BIANCHETTI, R. G. Modelo neoliberal e políticas educacionais & 2 \\
\hline BAZÍLIO, L. C.; EARP, M. de L. S.; NORONHA, P. A. (Orgs.). Infância tutelada e educação: história, política e legislação & 2 \\
\hline BRANDÃO, C. da F. Estrutura e Funcionamento do Ensino & 2 \\
\hline CASTRO, M. L. 0. de. A educação na Constituição de 1988 e a LDB & 2 \\
\hline COSTA, M. A educação nas constituições do Brasil: dados e direções & 2 \\
\hline CURY, C. R. J. Legislação educacional brasileira & 2 \\
\hline FERNANDES, F. Educação e sociedade no Brasil & 2 \\
\hline FERNANDES, F. 0 desafio educacional & 2 \\
\hline FERREIRA, N. S. C.; AGUIAR, M. A. da S. (Orgs.). Gestão da educação: impasses, perspectivas e compromissos & 2 \\
\hline FREITAG, B. Escola, Estado e Sociedade & 2 \\
\hline GENTILI, P.; MCCOWAN, T. (Orgs.). Reinventar a escola pública: política educacional para um novo Brasil & 2 \\
\hline GENTILI, P. (Org.). Pedagogia exclusão: crítica ao neoliberalismo em educação & 2 \\
\hline HÖFLING, E. M. Estado e políticas (públicas) sociais & 2 \\
\hline KRAWCZYK, N.; CAMPOS, M. M.; HADDAD, S. O cenário educacional latino-americano no limiar do século XXI: reformas em debate & 2 \\
\hline LIBÂNEO, J. C. Democratização da escola pública & 2 \\
\hline MAINARDES, J. Análise de políticas educacionais: breves considerações teórico-metodológicas. & 2 \\
\hline MELCHIOR, J. C. de A. Mudanças no financiamento da educação no Brasil. & 2 \\
\hline NEVES, L. M. W. Educação e política no Brasil de hoje & 2 \\
\hline OLIVEIRA, D. A; DUARTE, M. R. T. (Orgs.). Política e trabalho na escola: administração dos sistemas públicos de educação básica & 2 \\
\hline OLIVEIRA, R. Portela de. Da universalização do ensino fundamental ao desafio da qualidade: uma análise histórica. & 2 \\
\hline RIBEIR0, M. L. S. História da educação brasileira: a organização escolar. & 2 \\
\hline SANTOS, C. R. dos. Educação escolar brasileira: estrutura, administração, legislação & 2 \\
\hline SANTOS, W. G. Cidadania e justiça & 2 \\
\hline SAVIANI, D. Educação brasileira: estrutura e sistema & 2 \\
\hline SAVIANI, D. Política e educação no Brasil & 2 \\
\hline SILVA JR., J. dos R. Reforma do Estado e da Educação no Brasil de FHC & 2 \\
\hline SILVA, T. T. da; GENTILI, P. (Orgs.). Escola S. A.: Quem ganha e quem perde no mercado educacional do neolibera & 2 \\
\hline
\end{tabular}

Fonte: Organizada pelos autores. 


\section{Considerações finais}

O presente artigo é de natureza introdutória e exploratória, visto que se trata de um campo ainda sem acúmulo de investigação. Mesmo reconhecendo que se trata de uma temática nova e ainda pouco explorada, podemos sintetizar alguns pontos que podem constituir uma agenda de pesquisa nessa área: a) análise do surgimento e do conteúdo das disciplinas e áreas que antecederam o que atualmente é considerado como Política Educacional (Administração Escolar, Administração da Educação, Educação Comparada); b) análise das nomenclaturas, carga horária, período de oferta, conteúdos propostos, bibliografia, livros de natureza didática (manuais); c) ensino de Política Educacional e formação de pesquisadores para esse campo; d) identificação das contribuições dessa disciplina para a formação de professores, entre outros aspectos.

A análise apresentada caracteriza-se por ser uma primeira aproximação com o tema e demanda uma análise mais abrange e aprofundada. Apesar de suas limitações, esse artigo permite concluir que se trata de uma área de pesquisa relevante, pois pode trazer informações importantes para a compreensão e melhoria tanto do ensino de Política Educacional quanto para a formação de pesquisadores para esse campo.

\section{Referências}

AZEVEDO, J. M. L. A educação como política pública. 1. ed. Campinas: Autores Associados, 1997.

BONALS, L. P.; ARENS, A. G. L.; TRUJILLO, A. R. P. La política educativa: un componente necesario en la formación de docentes que investigan sobre su práctica. In: ENCUENTRO LATINOAMERICANO DE PROFESORES DE POLÍTICA EDUCATIVA, 1., 2015, Guarulhos, SP. Anais... Guarulhos, SP: UNIFESP, 2015. p. 1-21.

BRUEL, A. L. de O. Políticas e legislação da educação básica no Brasil. Curitiba: Ibpex, 2010.

BRZEZINSKI, I. (Org.). LDB Interpretada: diversos olhares se entrecruzam. 1. ed. São Paulo: Cortez, 1997.

CARVALHO, E. J. G. de. Políticas públicas e gestão da educação no Brasil. Maringá: EDUEM, 2012.

CELLARD, A. A análise documental. In: POUPART, J. et al. A pesquisa qualitativa: enfoques epistemológicos e metodológicos. Tradução de Ana Cristina Nasser. 4. ed. Petrópolis, RJ: Vozes, 2014. p. 295-316. (Coleção Sociologia).

COSTA, A. de C.; MURANAKA, M. A. S.; BORGHI, R. F. A contribuição da disciplina PEB à formação de professores do ensino básico: estudo do caso das licenciaturas em uma universidade estadual. In: ENCUENTRO LATINOAMERICANO DE PROFESORES DE POLITICA EDUCATIVA, 1., 2015, Guarulhos, SP. Anais... Guarulhos, SP: UNIFESP, 2015. p. 1-24.

FLACH, S. de F.; MASSON, G. A disciplina de política educacional em cursos de formação de professores. In: ENCUENTRO LATINOAMERICANO DE PROFESORES DE POLITICA EDUCATIVA, 1., 2015, Guarulhos, SP. Anais... Guarulhos, SP: UNIFESP, 2015. p. 1-18.

FREITAS, H. et al. Sphinx Aprendiz. Canoas: Sphinx Brasil, 2008.

GIL, A. C. Métodos e técnicas de Pesquisa Social. 5. ed. São Paulo: Atlas, 1999.

GIL, A. C. Como elaborar projetos de pesquisa. 4. ed. São Paulo: Atlas, 2002.

KFOURI, S. F. Políticas educacionais: estruturas e sistemas. São Paulo: Pearson Education do Brasil, 2009. LIBÂNEO, J. C.; OLIVEIRA, J. F. de; TOSCHI, M. S. Educação escolar: políticas, estrutura e organização. 1. ed. São Paulo: Cortez, 2003.

MARTIGNONI, L. La enseñanza de la política educativa en la formación docente el caso de la carrera de Geografía. In: ENCUENTRO LATINOAMERICANO DE PROFESORES DE POLÍTICA EDUCATIVA, 1., 2015, Guarulhos, SP. Anais... Guarulhos, SP: UNIFESP, 2015. p. 1-13.

MARTINS, C. O que é política educacional. São Paulo: Brasiliense, 1993.

MENDES, V. O estudo da política educacional nos cursos de licenciatura de uma Instituição Federal de Ensino Superior. In: ENCUENTRO LATINOAMERICANO DE PROFESORES DE POLÍTICA EDUCATIVA, 1., 2015, 
Guarulhos, SP. Anais... Guarulhos, SP: UNIFESP, 2015. p. 1-21.

NEY, A. Política educacional: organização e estrutura da educação brasileira. Rio de Janeiro: Wak, 2008.

OLIVEIRA, R. P.; ADRIÃO, T. (Orgs.). Organização do ensino no Brasil: níveis e modalidades na Constituição Federal e na LDB. 1. ed. São Paulo: Xamã Editora, 2002.

PRONKO, M. A. Desafios teórico-metodológicos para o ensino de políticas educacionais na perspectiva do materialismo histórico. In: ENCUENTRO LATINOAMERICANO DE PROFESORES DE POLITICA EDUCATIVA, 1. 2015, Guarulhos, SP. Anais... Guarulhos, SP: UNIFESP, 2015. p. 1-17.

QUIANÉ, L. M. J.; LÓPEZ, V. M. S. El estudio de la política educativa en la maestría en educación básica de la Universidad Pedagógica Nacional-México: un relato reflexivo y crítico desde sus orígenes, diseño y operación. In: ENCUENTRO LATINOAMERICANO DE PROFESORES DE POLÍTICA EDUCATIVA, 1., 2015, Guarulhos, SP. Anais... Guarulhos, SP: UNIFESP, 2015. p. 1-19.

RICHARDSON, R. J. et al. Pesquisa social: métodos e técnicas. 3. ed. São Paulo: Atlas, 1999.

ROMERO, S. A.; GARCIA, M. G. Sentidos y desafíos de enseñar política educativa en la formación docente. In: ENCUENTRO LATINOAMERICANO DE PROFESORES DE POLITICA EDUCATIVA, 1., 2015, Guarulhos, SP. Anais... Guarulhos, SP: UNIFESP, 2015. p. 1-15.

SANTOS, P. S. M. B. dos. Guia prático da política educacional no Brasil: ações, planos, programas e impactos. São Paulo: Cengage Learning, 2012.

SAVIANI, D. A Nova Lei da Educação: trajetória, limites e perspectivas. 1. ed. Campinas: Autores Associados, 1997. SAVIANI, D. Da nova LDB ao FUNDEB. 1. ed. Campinas: Autores Associados, 2007.

SAVIANI, D. Da Nova LDB ao novo Plano Nacional de Educação. 1. ed. Campinas: Autores Associados, 1998. SHIROMA, E. O.; MORAES, M. C. M. de; EVANGELISTA, O. Política Educacional. 1. ed. Rio de Janeiro: DP\&A, 2000.

SOUZA, A. R. de; GOUVEIA, A. B.; TAVARES, T. M. (Orgs.). Políticas educacionais: conceitos e debates. Curitiba: Appris, 2011.

STREMEL, S.; MAINARDES, J. Reflexões iniciais sobre a disciplina política educacional em cursos de pedagogia no Brasil. In: ENCUENTRO LATINOAMERICANO DE PROFESORES DE POLÍTICA EDUCATIVA, 1., 2015, Guarulhos, SP. Anais... Guarulhos, SP: UNIFESP, 2015. p. 1-25.

TELLO, C. La enseñanza de la Política Educativa y la formación de investigadores en el campo. Entre las matrices históricas y la episteme de época. Revista de Educação Pública, Cuiabá, v. 24, n. 55, p. 125-151, jan./abr. 2015.

VIEIRA, S. L. Educação Básica: política e gestão da escola. Brasília: Liber Livro, 2009.

VIEIRA, S. L.; ALBUQUERQUE, M. G. M. Política e planejamento educacional. Fortaleza: Demócrito Rocha, 2001. VIEIRA, S. L.; FARIAS, I. M. S. de. Política educacional no Brasil: introdução histórica. Brasília: Líber Livro, 2007. VISACOVSKY, N. ¿Cómo enseñar política educativa desde un abordaje interdisciplinar? In: ENCUENTRO LATINOAMERICANO DE PROFESORES DE POLÍTICA EDUCATIVA, 1., 2015, Guarulhos, SP. Anais... Guarulhos, SP: UNIFESP, 2015. p. 1-12.

Recebido em Junho de 2015 | Aprovado em Julho de 2015 